\title{
Rabaska
}

Revue d'ethnologie de l'Amérique française

RICHARD, BÉATRICE (éd.). La Grande Guerre de Paul Caron.

Chroniques d'un légionnaire canadien-français (1914-1917). Québec, Presses de l'Université Laval, « L’Archive littéraire au Québec / série Monuments », 2014, 268 p. ISBN 978-2-7637-2139-2. / ANDRÈS, BERNARD. L'Humour des Poilus canadiens-français de la Grande Guerre. Québec, Presses de l'Université Laval, 2018, 174 p. ISBN 978-2-7637-3939-7

\section{Diane Joly}

Volume 17, 2019

URI : https://id.erudit.org/iderudit/1066044ar

DOI : https://doi.org/10.7202/1066044ar

Aller au sommaire du numéro

\section{Éditeur(s)}

Société québécoise d'ethnologie

ISSN

1703-7433 (imprimé)

1916-7350 (numérique)

Découvrir la revue

Citer ce compte rendu

Joly, D. (2019). Compte rendu de [RICHARD, BÉATRICE (éd.). La Grande Guerre de Paul Caron. Chroniques d'un légionnaire canadien-français (1914-1917). Québec, Presses de l'Université Laval, «L'Archive littéraire au Québec / série Monuments ", 2014, 268 p. ISBN 978-2-7637-2139-2. / ANDRÈs, BERNARD. L'Humour des Poilus canadiens-français de la Grande Guerre. Québec, Presses de l'Université Laval, 2018, 174 p. ISBN 978-2-7637-3939-7]. Rabaska, 17, 357-359. https://doi.org/10.7202/1066044ar d'utilisation que vous pouvez consulter en ligne. 
procédés de mise en œuvre d'une couverture de bardeau. Pour chaque partie de la couverture, les auteurs décrivent de quelle façon les bardeaux doivent être disposés en illustrant les procédés par un nombre important de figures. On se transporte ensuite au septième chapitre où sont présentés les différents supports de couvertures. Le lecteur y trouvera notamment des références au Code national du bâtiment et à l'Association des maîtres couvreurs. Le bâti ancien rejoint ici les normes actuelles de construction. Sous cet angle, le huitième chapitre traitant des produits de préservation et de finition fournit aux intervenants en construction ou en restauration des informations visant à enrichir celles des manufacturiers de ces produits. Pour conclure, le livre s'achève sur un chapitre abordant l'entretien et la réfection des ouvrages de bardeau de bois. L'entretien préventif, celle de la finition et les travaux de réfection y sont décrits. À des fins de références, les dernières pages renferment une bibliographie bien structurée et complète proposant un bon nombre de documents facilement accessibles sur le web.

Au-delà de l'esthétique irréprochable et de l'agréable format caractéristique de nombreux volumes parus aux Publications du Québec, le texte de Toit. Bois. Bardeau maintient une cohérence exemplaire, page après page, chapitre après chapitre. L'information offerte avec érudition progresse de façon logique et fluide. Les illustrations abondantes témoignent d'une parfaite uniformité, à l'image des pages qu'elles enrichissent. Sans jamais douter, le lecteur y puise une information précise, exhaustive et fiable qui reflète parfaitement l'indiscutable compétence des auteurs. Tout compte fait, ce guide technique rédigé par les experts du Centre de conservation du Québec constitue un ouvrage essentiel pour les propriétaires de bâtiments recouverts de bardeaux de bois, les entrepreneurs et les artisans, mais aussi pour tous les spécialistes œuvrant à la conservation du patrimoine architectural.

Sébastien LeduC

Archéologue et rédacteur

Richard, Béatrice (éd.). La Grande Guerre de Paul Caron. Chroniques d'un légionnaire canadien-français (1914-1917). Québec, Presses de l'Université Laval, «L'Archive littéraire au Québec / série Monuments », 2014, 268 p. ISBN 978-2-7637-2139-2. / ANDRÈs, BERNARD. L'Humour des Poilus canadiens-français de la Grande Guerre. Québec, Presses de l'Université Laval, 2018, 174 p. ISBN 978-2-7637-3939-7.

Les deux études rapportées ici abordent la vie du soldat dans les tranchées de la Première Guerre mondiale. L'historienne Béatrice Richard se spécialise dans les études culturelles de la guerre, en particulier l'attitude des Canadiens 
français face aux conflits armés et aux institutions militaires. Elle a un sujet en or avec Paul Caron, nationaliste ultramontain qui s'engage dans la légion étrangère de la France laïque. Pour sa part, Bernard Andrès, qui s'intéresse aux origines des lettres québécoises, dont l'archéologie de l'humour au Québec du XVII ${ }^{e}$ au XIX ${ }^{e}$ siècle, étudie l'humour associé à la Grande Guerre que l'on retrouve dans les écrits canadien-français de l'époque.

Béatrice Richard se demande quelle guerre peut bien raconter un Canadien français nationaliste dans une guerre impérialiste. Né à Montmagny en 1889 dans un milieu modeste, Paul Caron arrive à Montréal en 1909 avec l'intention de devenir journaliste. Il est rapidement embauché par le journal Le Devoir comme sténographe. Mais il devra attendre cinq longues années avant d'être publié dans une revue ultramontaine. Le jour même de la déclaration de la guerre en 1914, Caron quitte le journal et s'embarque pour la France pour laquelle il veut combattre. Sa « carrière journalistique » prend son envol à ce moment-là. Dès son engagement dans la légion étrangère, Caron écrit ses impressions sur le vif. Jusque-là, la guerre était rapportée par un témoin oculaire officiel ; l'approche intimiste de Caron pour décrire le conflit armé en fait un pionnier du reportage de guerre au Canada. Ses chroniques constituent également un témoignage exceptionnel dans la longue durée. Caron meurt au combat le 16 avril 1917.

Dans l'introduction, la chercheuse explique, à l'aide de plusieurs exemples, les nombreux enjeux qui se retrouvent dans les chroniques du soldat Caron. Ce dernier se présente comme un témoin oculaire tout en signalant qu'il traduit ses impressions personnelles. Cette autocensure s'applique entre autres à la description des champs de bataille qu'il est impossible de décrire de façon réaliste dans un texte voué à la publication. La brutalité de la guerre est plus souvent suggérée que montrée. L'ironie et la désinvolture est une autre stratégie pour décrire la vie horrible du fantassin dans les tranchées. On va ainsi associer le camp de bûcherons à la vie des tranchées ou s'extasier sur le confort de la grange pour dormir. Publiées dans le Peuple de Montmagny, un hebdomadaire conservateur patriotard et chauvin, ainsi que dans Le Devoir, un quotidien indépendant et résolument opposé à la propagande de guerre, les 33 chroniques, sur environ 25 mois, sont présentées selon un ordre chronologique sous un titre qui décrit la carrière militaire de Paul Caron - du jeune homme en quête d'un régiment avec « Lettre de France » au nouveau soldat avec le « Carnet du légionnaire », puis « du lignard », « du fourrier » et en dernier « de l'aspirant» (officier). Dans ses textes, il parle du sentiment d'appartenance, des camarades, des petits plaisirs et des difficultés du quotidien, de l'incertitude face à l'avenir et de sa désensibilisation croissante face à la mort. 
En plus de situer les écrits du soldat dans leur contexte géographique, les commentaires de Béatrice Richard sont éclairants sur la dimension idéologique de l'engagement de Caron. À ce travail remarquable s'ajoutent les notes, la bibliographie, l'index général et la liste des illustrations qui constituent une base solide pour des recherches approfondies sur l'une des problématiques soulevées par la chercheuse. C'est ce que fera d'ailleurs Bernard Andrès qui aborde spécifiquement l'humour des Poilus canadiensfrançais pendant la Grande Guerre.

D'entrée de jeu, celui-ci rappelle que près de $10 \%$ de l'ensemble des Canadiens mobilisés sont mort au cours de la Première Guerre mondiale. Le chercheur s'intéresse aux Poilus, ou le Poil-aux-Pattes, ce vaillant soldat des tranchées qui cohabite avec les poux et les rats, et qui vit sous la menace constante du tir ennemi. Les cartes, l'écriture et les chansons composent ses petites distractions pendant les trêves. L'humour, que l'on retrouve dans les écrits et les dessins, joue un rôle important dans le moral et la résilience des Poilus. C'est cet enjeu que veut comprendre Bernard Andrès : comment l'humour permet aux soldats de survivre psychologiquement pendant un conflit mettant en jeu leur vie et leur patriotisme. Pour ce faire, l'auteur a revu les témoignages publiés de soldats canadiens, les articles de journaux, les documents militaires et les études sur le sujet ; il analyse ainsi les écrits d'auteurs reconnus pour leur contribution au corpus littéraire canadienfrançais de la Grande Guerre.

L'ouvrage se divise en deux parties. En premier, l'auteur étudie le corpus canadien-français du conflit, dont les textes de Paul Caron sur lequel l'auteur s'appuie tout au long de son étude. Il choisit d' analyser la guerre vue d'en bas, c'est-à-dire racontée à chaud ou au lendemain des événements, toujours sous l'angle de l'humour. Selon l'auteur, le conflit mobilise leur courage et leur dévouement tout en questionnant leur allégeance. Pour qui se battent-ils, le Canada, l'Angleterre ou la France ? Et de quelle France au juste ? Plusieurs Canadiens français protestent contre leur mobilisation pour l'Angleterre ; d'autres sont mal à l'aise avec une France républicaine qui confronte leurs convictions religieuses. En deuxième partie, il reprend le témoignage de deux infirmiers, un rédacteur et un caricaturiste, qui tentent par le rire de valoriser les soldats du rang, les valeurs des Canadiens français et l'honneur de leur unité. L'ouvrage est bonifié de plusieurs dessins, esquisses et extraits qui permettent de mieux saisir les enjeux typiquement canadiens-français associés à la Première Guerre mondiale. Bernard Andrès s'est mérité le Prix du Livre d'humour et de résistance 2019 par la Maison du rire et de l'humour. 